\title{
Energetics of Electron Transfer at the Nanocrystalline Titanium Dioxide Semiconductor/ Aqueous Solution Interface: pH Invariance of the Metal-Based Formal Potential of a Representative Surface-Attached Dye Couple
}

\author{
Susan G. Yan and Joseph T. Hupp* \\ Department of Chemistry and Materials Research Center, Northwestern University, Evanston, Illinois 60208 \\ Received: October 18, $1996^{\otimes}$
}

\begin{abstract}
Mediator-based spectroelectrochemical assessment of the metal-centered formal potential $\left(E_{\mathrm{f}}^{\mathrm{Ru}}\right)$ of a representative inorganic dye, $\mathrm{Ru}\left(4,4^{\prime}-\left(\mathrm{CH}_{2} \mathrm{PO}_{3}\right)-2,2^{\prime} \text {-bipyridine }\right)_{3}{ }^{10-}$, bound to a nanocrystalline titanium dioxide film shows that the potential is insensitive to changes in solution $\mathrm{pH}$, despite significant shifts in the conduction band edge energy $\left(E_{\mathrm{CB}}\right)$ of the underlying semiconductor electrode in response to the same environmental perturbations. The observations are important in the context of recent work showing that back-electron reactivity for the same semiconductor/dye combination is $\mathrm{pH}$ independent over a $19 \mathrm{pH}$ unit range, despite apparent changes in back-reaction driving force of greater than $1.2 \mathrm{eV}$ over the same interval (Yan, S.; Hupp, J. T. J. Phys. Chem. 1996, 100, 6867). In particular, the spectroelectrochemical findings serve to rule out a suggested alternative interpretation of the unusual kinetic effects whereby the crucial energy difference quantity, $E_{\mathrm{CB}}-E_{\mathrm{f}}^{\mathrm{Ru}}$, remains fixed because of compensating changes in the dye potential with $\mathrm{pH}$.
\end{abstract}

\section{Introduction}

Inorganic dye sensitization of wide band gap semiconductors has attracted tremendous recent attention because of the possibility of relatively efficient visible light to electrical energy conversion in photoelectrochemical cells that employ these assemblies. ${ }^{1}$ The assemblies are also of interest because of their ability to offer insight into the fundamental kinetics and dynamics of fast interfacial redox processes. ${ }^{2}$ Recently we reported on the kinetics for back-electron transfer from $\mathrm{TiO}_{2}$ to a hexaphosphonated form of ruthenium tris(bipyridine), following light-induced forward electron injection from a chargetransfer excited state of the metal complex. ${ }^{3}$ Hexaphosphonation served to facilitate strong surface attachment, thereby permitting the reaction to be examined over an extremely wide $\mathrm{pH}$ range., The surprising finding was that the back-ET kinetics were $\mathrm{pH}$ independent, ${ }^{3}$ despite the known Nernstian dependence of the $\mathrm{TiO}_{2}$ conduction band edge energy $\left(E_{\mathrm{CB}}\right)$ on solution $\mathrm{pH} .^{5}$ Indeed, over the $\mathrm{pH}$ range examined, the nominal strength of $\mathrm{TiO}_{2}$ as a reductant varied by more than $1.2 \mathrm{eV} .{ }^{3}$ The striking decoupling of the ET kinetics from the $\mathrm{pH}$-variable energetics was speculatively interpreted in terms of a sequential electron transfer/proton transfer process where (a) the isolated electron transfer event ( $\mathrm{pH}$ independent) defined the rate-determining dynamics, but (b) the combined processes ( $\mathrm{pH}$ dependent) determined the overall reaction energetics. Supporting evidence for the interpretation was garnered from quartz crystal microbalance experiments which independently showed that proton transfer (intercalation) accompanies both electrochemical and photochemical addition of electrons to the titanium dioxide conduction band or nearby surface states. ${ }^{6}$

An interesting alternative interpretation of the $\mathrm{pH}$-independent kinetics is that the formal potential for the ruthenium dye $\left(E_{\mathrm{f}}^{\mathrm{Ru}}\right)$ acquires a $\mathrm{pH}$ dependence upon confinement to the semiconductor surface. ${ }^{7}$ If this $\mathrm{pH}$ dependence precisely followed the $\mathrm{pH}$ dependence of the conduction band edge, the difference quantity $\left(E_{\mathrm{CB}}-E_{\mathrm{f}}^{\mathrm{Ru}}\right)$ obviously would be $\mathrm{pH}$ independent. It would then likely be unnecessary to invoke sequential electron and proton transfer to account for the otherwise puzzling reaction kinetics. Candidate mechanisms for induction of $\mathrm{pH}$-dependent

\footnotetext{
${ }^{\otimes}$ Abstract published in Advance ACS Abstracts, December 15, 1996.
}

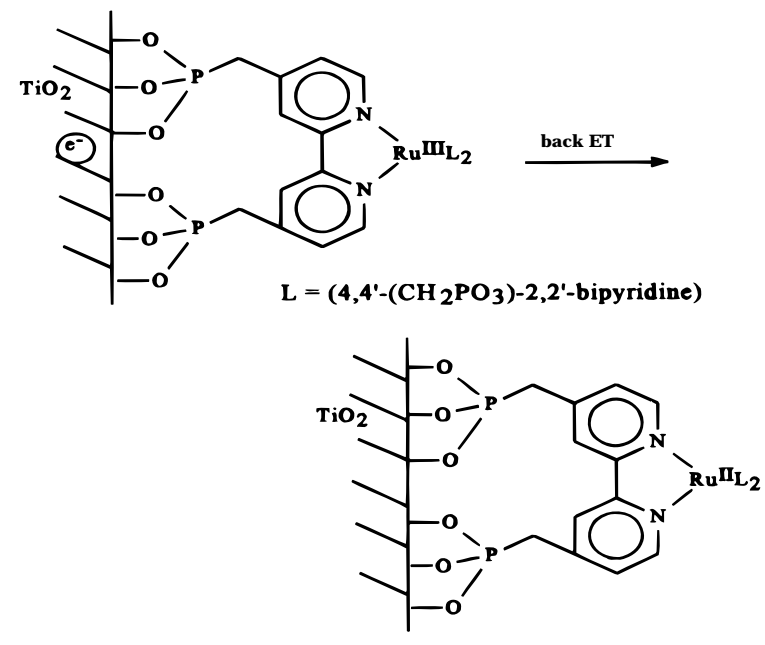

dye energetics ${ }^{7}$ could include (a) strong electronic coupling between formally metal-dye-localized electronic states and the titanium dioxide conduction band or (b) Coulombic perturbation of $E_{\mathrm{f}} \mathrm{Ru}$ by surface oxide/hydroxide protonation and deprotonation processes. The former seems highly unlikely in view of the six-atom (seven-bond) "bridge" separating the redox-active ruthenium center from surface titanium atoms in the phosphonated dye/semiconductor assembly (eq 1). The latter mechanism is also problematic, however, unless the primary mechanism for conduction band edge energy tuning is also Coulombic perturbation (i.e., essentially a double-layer effect). We have suggested elsewhere that $\mathrm{pH}$-based $E_{\mathrm{CB}}$ tuning is instead achieved primarily via a "Pourbaix" type effect where electron addition induces the intercalation of charge-compensating cations. In any case, evaluation of the $\mathrm{pH}$ dependence of the formal potential for a surface-bound dye would provide an important test of the viability of the alternative explanation of the anomalous ET rate phenomenon.

We describe below a study of the $\mathrm{pH}$ dependence of $E_{\mathrm{f}}$ for a representative redox dye, $\mathrm{Ru}\left(4,4^{\prime}-\left(\mathrm{CH}_{2} \mathrm{PO}_{3}\right)-2,2^{\prime} \text {-bipyridine }\right)_{3}{ }^{10-}$, bound to a high-area titanium dioxide electrode. The study shows that the potential is approximately $\mathrm{pH}$ independent, supporting our original contention and supporting-at least, 
indirectly - the Pourbaix interpretation of conduction band edge energy modulation.

\section{Experimental Section}

Materials. High-area nanocrystalline titanium dioxide electrodes were prepared in thin film form via the following procedure $^{8}$ which is a variant of a method described by O'Regan et al. ${ }^{9}$ Over a $2 \mathrm{~min}$ period $30 \mathrm{~mL}$ of $\mathrm{Ti}\left(\mathrm{OCH}\left(\mathrm{CH}_{3}\right)_{2}\right)_{4}$ (Aldrich) was added dropwise to a stirring solution of nitric acid (2.6 $\mathrm{mL}$ ) in $375 \mathrm{~mL}$ of deionized water. Stirring was continued for $2 \mathrm{~h}$ at ambient temperature, followed by $8 \mathrm{~h}$ at $80{ }^{\circ} \mathrm{C}$ to evaporate the propanol formed. The resulting sol was heated for an additional $12 \mathrm{~h}$ at $200{ }^{\circ} \mathrm{C}$ in a stainless steel pressure vessel. Water was removed by rotary evaporation until a sol concentration of $160 \mathrm{~g} / \mathrm{L}$ was achieved. Carbowax $20000(40 \%$ weight equivalent of $\mathrm{TiO}_{2}$ ) was added to the concentrated sol, and the mixture was stirred overnight. Films were prepared by spin coating the sol onto conductive glass (fluorine-doped tin oxide; Asahi) followed by annealing for $1 \mathrm{~h}$ in air at 400 ${ }^{\circ} \mathrm{C}$.

The ruthenium-based dye was prepared as a nominally hexaphosphoester species as previously described. . $^{3,10,11}$ Conversion to the diphosphonate was accomplished by acidcatalyzed hydrolysis in $6 \mathrm{M}$ aqueous $\mathrm{HCl}$ (minutes). The solvent was then removed by rotary evaporation. The dye residue was redissolved in $5 \mathrm{mM} \mathrm{HNO}_{3}$ in water $(\mathrm{pH}=2.45)$. The surface attachment procedure consisted of soaking nanocrystalline film electrodes in the acidified dye solution for 24 h.

$\left[\mathrm{Fe}(\mathrm{phen})_{3}\right]\left(\mathrm{PF}_{6}\right)_{2}$ (phen is 1,10 -phenanthroline) was prepared by a literature method. ${ }^{12}$

Methods. Electrochemical measurements were initially made in a one-compartment cell featuring either a titanium dioxide or indium-doped tin oxide ("conductive glass") working electrode, a platinum wire counter electrode, and a saturated $(\mathrm{NaCl})$ calomel reference electrode (s.s.c.e.). Potentials were controlled with a PAR 264A potentiostat. Cyclic voltammograms were recorded at $100 \mathrm{mV} / \mathrm{s}$. Visible-region spectrochemical measurements were made by using an HP 8452 A diode array spectrophotometer together with cofacial glass/conductive glass or titanium dioxide/conductive glass assemblies featuring $\sim 100$ $\mu \mathrm{m}$ Teflon spacers. In the assemblies, only the conductive glass component was employed as a working electrode component. Filling of the assemblies was achieved via capillary action. Aqueous electrolyte solutions for studies at either $\mathrm{pH} 4$ or 7, respectively, contained either $50 \mathrm{mM}$ potassium hydrogen phthalate or $50 \mathrm{mM} \mathrm{KH_{2 }} \mathrm{PO}_{4}$, together with $\mathrm{Fe}(\text { phen })_{3}{ }^{2+}$ as a redox mediator. For measurements at other $\mathrm{pH}$ values, appropriate amounts of $\mathrm{HNO}_{3}$ or $\mathrm{NaOH}$ were added. At the lowest $\mathrm{pH}$ values, however, the buffer component was omitted.

\section{Results and Discussion}

Formal potentials for the surface-bound ruthenium dye were initially estimated simply by recording cyclic voltammograms. The voltammetry experiments yielded small reversible surfacetype waves whose potentials were invariant with $\mathrm{pH}$ over the range from 1 to 8 ; i.e., evidence for coupling to the $\mathrm{pH}$ dependent conduction band energetics of the titanium dioxide electrode was not found. A point of concern, however, is that in the potential region where dye oxidation occurs the semiconductor is nominally insulating. While the observed surface redox waves could be due to leakage currents associated with midgap states, they conceivably also could arise from oxidation and reduction of dye molecules that interact directly with the underlying conductive glass surface (for example, via pinhole defects). In view of the typically small sizes of the waves and the correspondingly small amount of dye oxidized, the pinhole interpretation is difficult to discount. Consequently, we sought

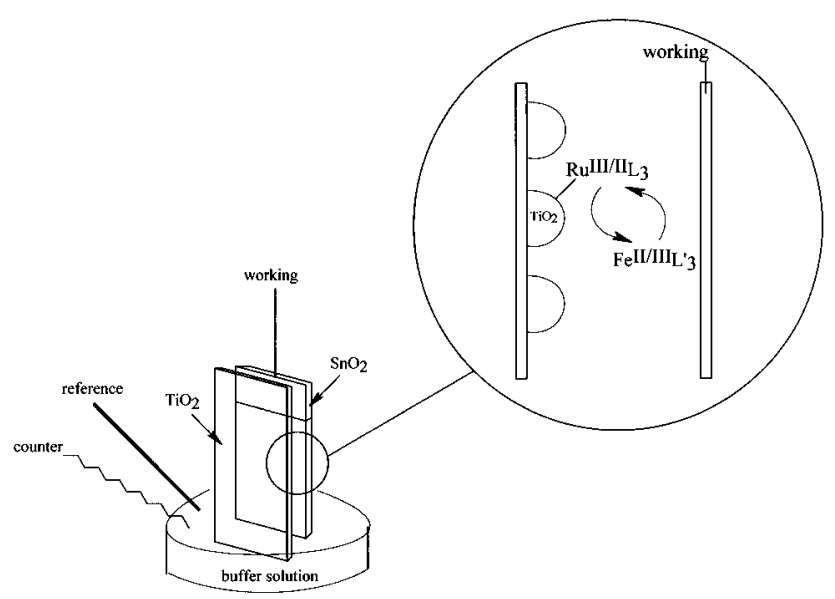

Figure 1. Schematic depiction of the thin-layer spectroelectrochemical cell and associated redox mediation scheme.

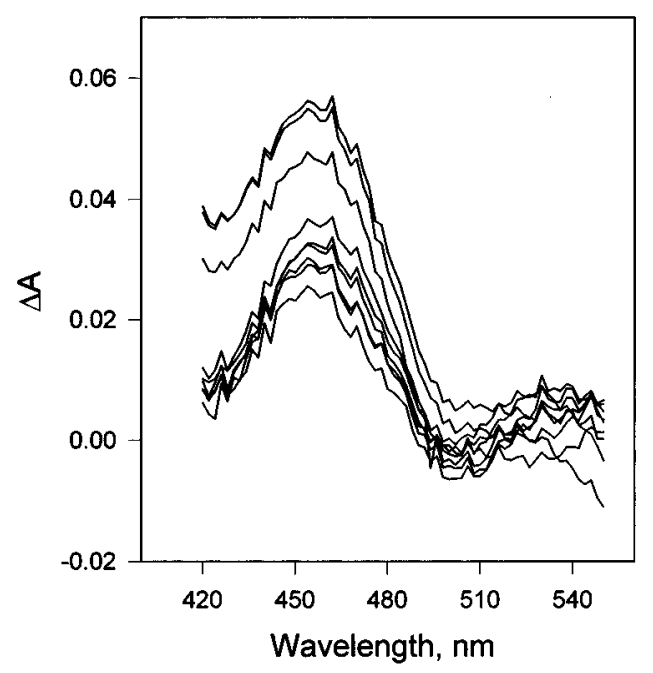

Figure 2. Dye-functionalized thin-layer cell absorbances versus a blank cell lacking the dye but containing a titanium dioxide film. Absorbance differences are shown at $\mathrm{pH}=4$ and are recorded with the mediator solution poised at 0.3 (top curve), 0.5, 0.7, 0.8, 0.9, 0.95, 1.0, 1.1, and $1.3 \mathrm{~V}$ (bottom curve). Spectra have been corrected for residual mediator absorbance.

an alternative method that would enable us to determine the average potential for the entire collection of dye molecules residing on an insulating substrate.

Figure 1 illustrates the second approach. Surface-bound dye molecules are indirectly addressed via interactions with a freely diffusing redox mediator, $\mathrm{Fe}($ phen $) 3^{3+/ 2+}$. This mediator was chosen because of the proximity of its formal potential $(0.83$ $\mathrm{V})$ to the anticipated dye potential. The exact potential of the dye was determined spectrally by (a) poising the thin-layer cell solution at a predetermined potential, (b) allowing the surfacebound dye to equilibrate with the poised mediator solution, (c) determining spectrally the fractions, $f($ III) and $f($ II), of dye in oxidized and reduced form, respectively, and (d) repeating steps $\mathrm{a}-\mathrm{c}$ at a new potential. The resulting data were then fit graphically to the Nernst equation written in the following form: 13

$$
E_{\mathrm{f}}^{\mathrm{Ru}}=E(\text { poised })-(R T / F) \ln \{f(\mathrm{III}) / f(\mathrm{II})\}
$$

Interference from the mediator was avoided both via the offset of the mediator absorption $\left(\lambda_{\max }=550 \mathrm{~nm}\right)$ from the dye absorption $\left(\lambda_{\max }=460 \mathrm{~nm}\right)$ and by utilizing an extremely short solution path length. In some cases spectra were also corrected for residual mediator absorbance effects by running blank experiments in spectroelectrochemical cells lacking the ruthenium dye. 


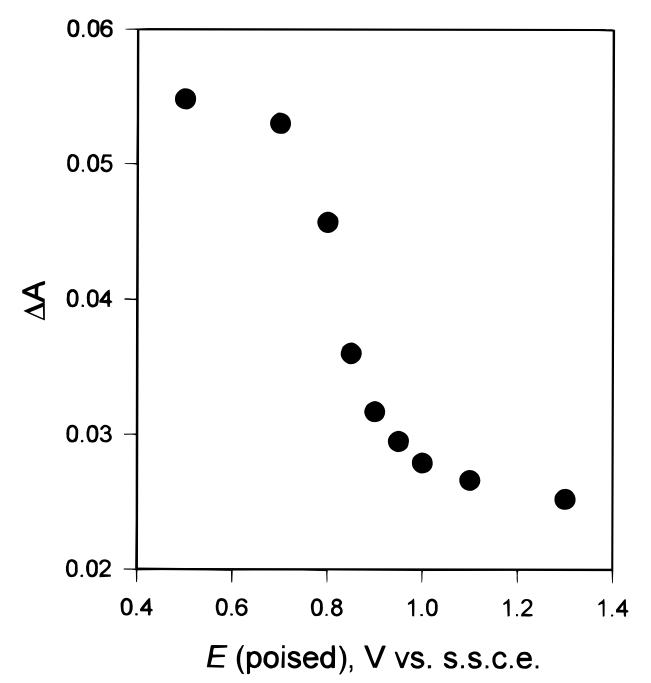

Figure 3. Absorbance changes at $460 \mathrm{~nm}$ versus poised potential of the thin-layer mediator solution at $\mathrm{pH}=4$.

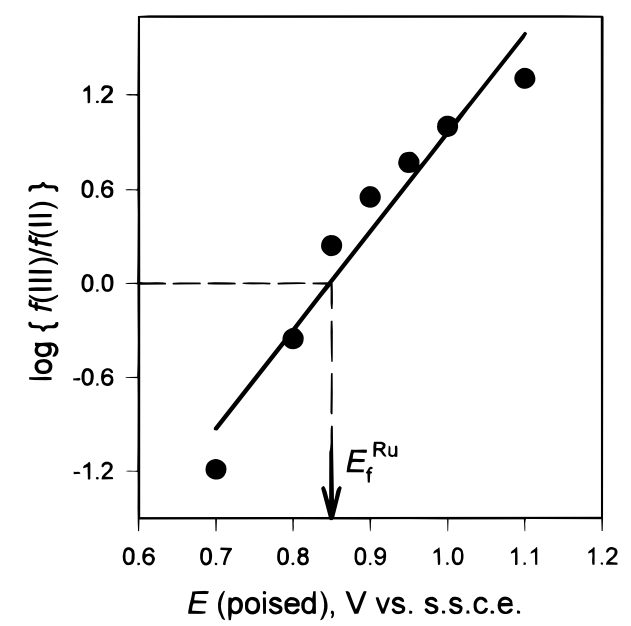

Figure 4. Plot of $\log \{f(\mathrm{III}) / f(\mathrm{II})\}$ versus poised potential of the thinlayer mediator solution at $\mathrm{pH}=4$. From the $y$ intercept, $E_{\mathrm{f}}{ }^{\mathrm{Ru}}$ is 0.86 $\mathrm{V}$ versus s.s.c.e.

Figure 2 shows a representative series of filmed-based spectral plots. Figure 3 illustrates how the resulting film absorbance varies as a function of the potential of the mediator solution. Figure 4 shows a graph based on eq 2, where the $y$ intercept provides a measure of $E_{\mathrm{f}}^{\mathrm{Ru}}$. Finally, Figure 5 summarizes the results of several such measurements over the $\mathrm{pH}$ range of $1.1-$ 8.75. Attempts to extend the experiments to $\mathrm{pH}$ values of -1 and -4 (sulfuric acid solutions) were frustrated by decomposition of the mediator, while attempts to extend the measurements to $\mathrm{pH}=10$ were circumvented by dye desorption. Nevertheless, over the accessible solution compositional range, the formal potential of the surface-bound dye is essentially fully $\mathrm{pH}$ independent, despite demonstrated shifts in $E_{\mathrm{CB}}$ of ca. -450 $\mathrm{mV}$ over the same $\mathrm{pH}$ range. ${ }^{3,15}$

Coupling of $E_{\mathrm{f}}^{\mathrm{Ru}}$ to $E_{\mathrm{CB}}$ would have been expected if $\mathrm{pH}$ dependent variations in the latter were determined primarily by simple Coulombic effects arising from surface oxide and hydroxide protonation and deprotonation equilibria. On the other hand, if $E_{\mathrm{CB}}$ were instead modulated primarily via stoichiometric proton intercalation following electron addition, ${ }^{6}$ little or no coupling to $E_{\mathrm{f}}^{\mathrm{Ru}}$ would be expected. Regardless of the expectations, however, the experimentally observed invariance of $E_{\mathrm{f}}^{\mathrm{Ru}}$ with respect to solution $\mathrm{pH}$ serves to rule out the trivial "energy compensation" explanation (see Introduction) for the remarkable insensitivity of previously reported ${ }^{3}$ back-

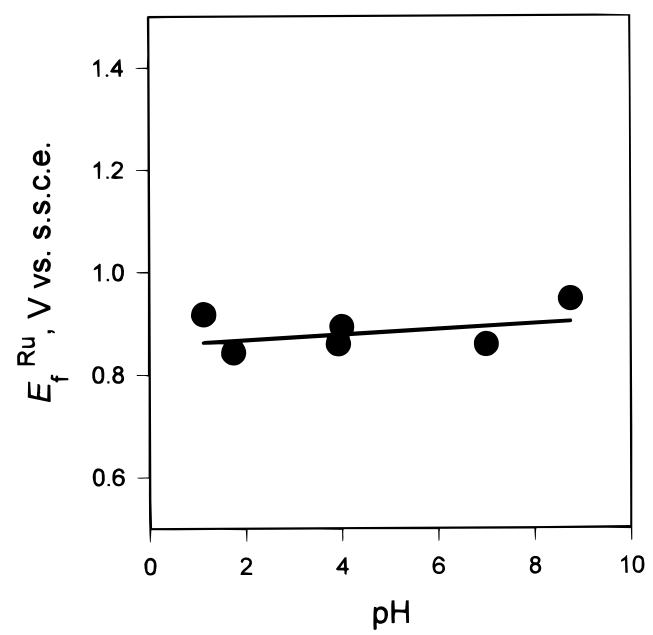

Figure 5. Plot of spectrally determined formal potential for the titanium-dioxide-immobilized ruthenium dye (see Figure 4) versus solution $\mathrm{pH}$. Line drawn is a best fit line (slope $=+5 \mathrm{mV}$ per $\mathrm{pH}$ unit).

electron transfer rates (titanium dioxide to attached $\mathrm{Ru}(\mathrm{III}) \mathrm{L}_{3}$ ) to $\mathrm{pH}$-induced changes in $E_{\mathrm{CB}}$.

Acknowledgment. We thank Dr. Brian Gregg for drawing our attention to several of the issues discussed here and for sending a preprint of ref $7 \mathrm{~b}$. We thank Prof. Nate Lewis and Dr. Steven Doig for advice on the preparation of high-area semiconductor electrodes. We gratefully acknowledge the Office of Naval Research for financial support and the Northwestern Materials Research Center (NSF DMR-9120521) for fellowship support for S.G.Y.

\section{References and Notes}

(1) For recent reviews, see: (a) Hagfeldt, A.; Grätzel, M. Chem. Rev. 1995, 95, 49. (b) Kamat, P. V. Chem. Rev. 1993, 93, 267. (c) Meyer, G. J.; Searson, P. C. Interface 1993, 23. (d) Parkinson, B. A.; Spitler, M. T. Electrochim. Acta 1992, 37, 943. 4927.

(2) Lu, H.; Prieskorn, J.; Hupp, J. T. J. Am. Chem. Soc. 1993, 115,

(3) Yan, S. G.; Hupp, J. T. J. Phys. Chem. 1996, 100, 6867.

(4) See also: Pechy, P.; Rotzinger, F. P.; Nazeeruddin, M. K.; Kohle, O.; Zakeeruddin, S. M.; Humphry-Baker, R.; Grätzel, M. J. Chem. Soc., Chem. Commun. 1995, 65.

(5) See, for example: (a) Bolts, J. M.; Wrighton, M. S. J. Phys. Chem. 1976, 80, 2641. (b) Watanabe, T.; Fujishima, A.; Tatsuoki, O.; Honda, K. Bull. Chem. Soc. Jpn. 1976, 49, 8. (c) Gerischer, H. Electrochim. Acta 1989, 34, 1005. (d) Hardee, K. L.; Bard, A. J. J. Electrochem. Soc. 1975, 122, 739 .

(6) (a) Lyon, L. A.; Hupp, J. T. J. Phys. Chem. 1995, 99, 15718. (b) Lemon, B. I.; Hupp, J. T. J. Phys. Chem. 1996, 100, 14578.

(7) (a) Gregg, B. A. Personal communication. (b) Zaban, A.; Ferrere, S.; Sprague, J.; Gregg, B. A. J. Phys. Chem., in press.

(8) Lewis, N. S.; Doig, S. Personal communication

(9) O'Regan, B.; Moser, J.; Anderson, M.; Grätzel, M. J. Phys. Chem. 1990, 94,8720 .

(10) Hirao, T.; Maunga, T.; Ohshiro, Y.; Agawa, T. Synthesis 1981, 56.

(11) ${ }^{1} \mathrm{H}$ NMR characterization of a previous preparation showed evidence for hydrolysis of some of the phosphoester functionalities prior to intentional acid-catalyzed hydrolysis. ${ }^{3}$

(12) Fussa-Rydel, O.; Zhang, H.-T.; Hupp, J. T.; Leidner, C. R. Inorg. Chem. 1989, 28, 1533.

(13) As expected if the spectroelectrochemical methodology were functioning reliably, the value obtained for $E_{\mathrm{f}}^{\mathrm{Ru}}$ was unaffected by replacement of the mediator by a second mediator couple ( $\mathrm{Fe}$ (5-chloro1,10-phenanthroline) $\left.3^{2+13+}\right)^{12}$ displaying a different formal potential.

(14) The required $f($ II) and $f($ III) values were obtained from Figure 3 by assuming that $f(\mathrm{III})$ is unity at the most positive potential and that $f(\mathrm{II})$ is unity at the least positive potentials. This approach corrects for errors due to incorrect background subtraction, residual absorbance by inaccessible $\mathrm{Ru}(\mathrm{II})$, and/or residual absorbance by $\mathrm{Ru}(\mathrm{III})$.

(15) An approximately $\mathrm{pH}$-invariant surface formal potential was also observed (via mediated spectroelectrochemistry) for a second complex featuring a pair of 5-nitro-1,10-phenanthroline ligands in place of two of the three available diphosphonated bipyridine ligands. 